\title{
SIKAP BAHASA PENUTUR BAHASA JATI DAN APARAT PEMERINTAH TERHADAP BAHASA RETTA DI ALOR
}

\author{
Language Attitude of Native Speakers and Government Apparatus Towards Retta
} Language in Alor

\section{Wati Kurniawati}

Badan Pengembangan dan Pelindungan Bahasa

Pos-el: watikurniawati62@yahoo.com

\begin{abstract}
Abstrak
Penelitian ini bertujuan untuk mengetahui sikap bahasa penutur dan aparat pemerintah terhadap bahasa ibunya. Metode yang digunakan adalah metode deskriptif dan analisis teks. Metode analisis teks yang digunakan adalah analisis isi. Pengumpulan data dilakukan dengan kuesioner dan metode cakap dengan teknik dasar berupa teknik pancing dan teknik lanjutan berupa teknik cakap semuka. Sampel penelitian ini berjumlah 90 responden dan 10 responden. Temuan penelitian ini memperlihatkan bahwa penutur bahasa Retta memiliki sikap positif terhadap bahasa ibunya karena melakukan transmisi bahasa ibu antargenerasi, digunakan dalam kehidupan sehari-hari, dan menjaga kelestariannya. Sementara itu, aparat pemerintah memiliki sikap positif terhadap bahasa Retta yang menyatakan bahwa bahasa Retta lebih bertahan hidup, ada generasi penerus sebagai penutur, bahasa leluhur, dipelajari untuk mempererat hubungan kekeluargaan, dan untuk muatan lokal di wilayahnya.
\end{abstract}

Kata kunci: analisis isi, kuesioner, responden, transmisi bahasa ibu

\begin{abstract}
This research aims to discover the language attitude of the native speakers and authorities towards their mother language. The methods used in this research are descriptive and text analysis methods. Text analysis method used is content analysis. Data collection was conducted through questionnaire and conversation method with fishing technique as the basic technique and face-to-face conversation technique as the continuation technique. The number of the samples is 90 respondents and 10 respondents. The research shows that the native speakers of Retta have a positive attitude towards their mother language since they transmit their mother language intergenerational, use it in their daily life and preserve it. In addition, the authorities also have a positive attitude towards their mother language. It indirectly states that Retta language is able to survive, there is the next generation as its speakers, it is an ancestral language and it is studied to strengthen the family relationships and as the local content.
\end{abstract}

Keywords: content analysis, questionnaire, respondent, mother language transmission

\section{PENDAHULUAN}

Bahasa Retta dituturkan oleh penduduk di Pulau Pura Selatan, yaitu di Desa Pura. Selain itu, bahasa Retta dituturkan oleh penduduk di Pulau Ternate, yaitu di Desa 
Ternate Selatan, Kecamatan Alor Barat Laut, Kabupaten Alor, Provinsi Nusa Tenggara Timur. Menurut Grimes (2010), bahasa Reta dituturkan oleh masyarakat di Teluk Kalabahi, yaitu di Pulau Pura dan Pulau Ternate Selatan. Jumlah penutur bahasa Reta sekitar 800 penutur. Status bahasa Reta adalah terancam. SIL Internasional (2006) menyatakan bahwa kelas bahasa Retta adalah Trans-New Guinea, bagian Selatan Kepala Burung, Timor-Alor-Pantar, Timor-Alor-Pantar, Makasai-Alor-Pantar, dan Pantar.

Vitalitas bahasa Retta di Ternate Selatan berdasarkan rerata kesepuluh indeks (penutur/ IP, kontak bahasa/IKB, bilingualism/IB, posisi dominan/IPD, ranah penggunaan bahasa/ IRPB, sikap bahasa/SB, regulasi/IR, pembelajaran/IPem, dokumentasi/ID, tantangan baru/ ITB) menunjukkan bahwa responden berdasarkan lama tinggal (lebih dari 10 tahun), suku bangsa (Retta), atau tempat lahir (di Ternate Selatan) cenderung sangat kritis dan terancam; terancam punah; mengalami kemunduran; stabil, tetapi berpotensi mengalami kemunduran (Kurniawati, 2015). Oleh karena itu, perlu dilakukan penelitian sikap bahasa penutur dan aparat pemerintah terhadap bahasa Retta.

Masalah dalam penelitian ini adalah bagaimana sikap bahasa penutur dan aparat pemerintah terhadap bahasa Retta. Tujuan dalam penelitian ini ialah untuk mengetahui sikap bahasa penutur dan aparat pemerintah terhadap bahasa Retta. Pengumpulan data dilaksanakan di Desa Ternate Selatan, Kecamatan Alor Barat Laut, Kabupaten Alor, Provinsi Nusa Tenggara Timur.

Anderson (1985) membedakan sikap bahasa dalam pengertian sempit dan luas. Sikap bahasa dalam arti sempit dipandang sebagai suatu konsep bersifat satu dimensi, yaitu dimensi rasa yang ada pada diri seseorang terhadap suatu bahasa. Sikap bahasa dalam arti luas berhubungan dengan isi makna sikap dan tanggapan yang mungkin ada, selain segi evaluatif dari sikap. Menurut Suhardi (1996:35), sikap bahasa meliputi sikap penutur bahasa terhadap pemakaian bahasa atau bahasa sebagai lambang kelompok. Sementara itu, konsep sikap dalam ilmu psikologi diadopsi oleh ilmu linguistik untuk menjelaskan bilingualisme. Seorang penutur dalam kondisi bilingual diasumsikan mempunyai sikap yang berbeda terhadap bahasa atau varian bahasa yang dikuasainya. Sikap itu dipengaruhi oleh konteks tutur dan penilaiannya pada bahasa tersebut. Menurut Cargile dalam Giles dan Billings (2004:187), bahasa adalah kekuatan sosial yang besar yang lebih dari sekadar penyampaian informasi referensial. Objek penelitian sikap bahasa berkaitan dengan ranah sosial yang diteliti. Sikap bahasa dalam penelitian ini adalah sikap penutur terhadap penggunaan bahasa sebagai identitas suku bangsa. Secara teoretis 
faktor-faktor sosial penutur, seperti jenis kelamin, usia, tingkat pendidikan, status sosial, dan mobilitas mempunyai pengaruh terhadap unsur bahasa yang dituturkan. Selain itu, faktor sosial penutur berpengaruh terhadap penerimaan dan pandangan atau sikap bahasa orang itu pada bahasa yang digunakannya serta bahasa lain yang ada di masyarakat tuturnya.

\section{METODOLOGI}

Pengumpulan data dilakukan dengan kuesioner dan metode cakap dengan teknik dasar berupa teknik pancing dan teknik lanjutan berupa teknik cakap semuka. Ayatrohaedi (2002) menyebut teknik ini metode pupuan lapangan. Populasi dalam penelitian ini adalah masyarakat tutur yang tinggal di Desa Ternate Selatan. Sampel penelitian ini berjumlah 100 responden. Responden sikap bahasa dalam penelitian ini berjumlah 90 orang (masyarakat Retta di Desa Ternate Selatan, Kabupaten Alor) dan responden aparat pemerintah berjumlah 10 orang (staf di Kabupaten Alor).

Faktor sosial penutur dalam penelitian ini adalah jenis kelamin dan kelompok usia. Komposisi responden berdasarkan jenis kelamin didominasi perempuan daripada laki-laki. Responden laki-laki berjumlah 35 orang $(38,9 \%)$ dan responden perempuan berjumlah $55(61,1 \%)$. Komposisi responden menurut karakteristik sosial adalah sebagai berikut.

\section{Tabel 1}

Komposisi Responden Berdasarkan Jenis Kelamin

\begin{tabular}{llll}
\hline No. & Jenis Kelamin & F & $\%$ \\
\hline 1. & Laki-laki & 35 & 38,9 \\
\hline 2. & Perempuan & 55 & 61,1 \\
\hline & Jumlah & 90 & 100 \\
\hline
\end{tabular}

Sementara itu, komposisi responden berdasarkan kelompok usia didominasi responden kelompok usia 26-50 tahun dibandingkan kelompok usia <25 tahun dan >51 tahun. Responden kelompok usia <25 tahun berjumlah 9 orang (10\%), kelompok usia 2650 tahun berjumlah 62 orang $(68,9 \%)$, dan kelompok usia $>51$ tahun berjumlah 19 orang $(21,1 \%)$. Tabel 2 berikut adalah komposisi responden menurut karakteristik sosial. 
Tabel 2 Komposisi Responden Berdasarkan Kelompok Usia

\begin{tabular}{llll}
\hline No. & Kelompok Usia & F & $\%$ \\
\hline 1. & $\leq 25$ tahun & 9 & 10 \\
\hline 2. & $26-50$ tahun & 62 & 68,9 \\
\hline 3. & $\geq 51$ tahun & 19 & 21,1 \\
\hline Jumlah & 90 & 100 \\
\hline
\end{tabular}

Instrumen penelitian terdiri atas dua bagian untuk sikap bahasa penutur, yaitu ciri responden dan butir tanyaan yang mengindikasikan sikap bahasa penutur bahasa Retta. Adapun intrumen sikap bahasa aparat pemerintah terhadap bahasa Retta terdiri atas dua bagian, yaitu ciri responden dan butir tanyaan yang mengindikasikan sikap bahasa aparat pemerintah terhadap bahasa Retta. Kuesioner dalam penelitian ini berisi tiga butir pertanyaan terhadap 90 responden bahasa Retta tentang pandangan penutur terhadap bahasanya dan sebelas butir pertanyaan terhadap 10 responden aparat pemerintah.

Indikator sikap bahasa mengacu pendapat Sugiyono dan Sry Satriya Tjatur Wisnu (2011:68 -69). Untuk mengukur sikap bahasa seseorang digunakan empat parameter, yaitu kemampuan, impresi, penggunaan, dan transmisi. Seseorang dianggap bersikap positif terhadap bahasa jika orang itu memiliki kemampuan dan impresi yang baik terhadap bahasa itu, masih menggunakan bahasa itu dalam berbagai ranah, dan mau mewariskan penggunaan bahasa tersebut kepada generasi berikutnya.

Dikatakan pula bahwa orang yang bersikap positif terhadap bahasa daerah, misalnya, orang itu harus mempunyai kemampuan yang baik dalam berbahasa daerah tersebut. Orang tersebut mahir berbicara, mendengarkan, menulis, dan membaca. Orang itu juga merasa senang dan bangga terhadap bahasa daerahnya yang direalisasikan dalam penggunaan bahasa sehari-hari dan mewariskannya kepada anak dan cucunya. Dengan adanya transmisi tersebut, bahasa daerah memiliki daya hidup atau vitalitas yang tinggi. 


\section{HASIL DAN PEMBAHASAN}

Sikap bahasa penutur terhadap cara agar bahasa daerah (BD) digunakan seharihari, baik oleh generasi sekarang maupun generasi yang akan datang beragam jawabannya. Penutur berpendapat dengan cara diajarkan kepada anak cucu, belajar bahasa daerah dari kecil, sering menggunakan bahasa Retta sehari-hari, membimbing generasi muda untuk berbahasa Retta, membimbing generasi muda untuk menggunakan bahasa Retta, menjaga bahasa Retta agar selalu digunakan generasi muda, memberi saran atau pesan kepada pemerintah agar bahasa ini bisa dirgunakan dengan baik, tetap dipertahankan, bahasa daerah sangat penting bagi kehidupan sekarang, membimbing mereka agar memahami bahasa Retta dengan baik, digunakan sesuai dengan situasi dan kondisi, diajarkan pada mata pelajaran mulok, dan disusun kamus bahasa Retta (Ternate Selatan). Berikut adalah parameter sikap bahasa penutur terhadap cara BD, yaitu bahasa Retta digunakan sehari-hari.

Tabel 3 Sikap Bahasa Penutur Terhadap Cara BD Digunakan Sehari-Hari

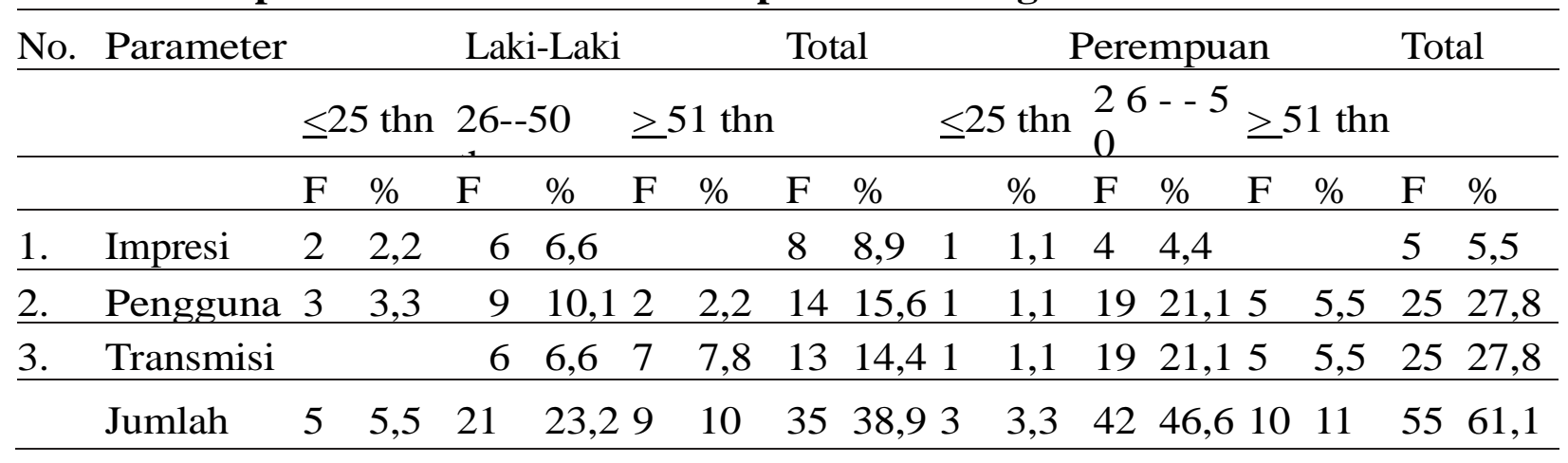


Tabel 3 memperlihatkan parameter impresi dan penggunaan pada penutur lakilaki kelompok usia 26-50 tahun tampak dominan, yaitu $6(6,6 \%)$ dan $9(10,1 \%)$. Parameter transmisi pada penutur laki-laki kelompok usia > 51 tahun tampak dominan, yaitu 7 (7,8\%). Sementara itu, parameter impresi, penggunaan, dan transmisi pada penutur perempuan kelompok usia 26-50 tahun tampak dominan, yaitu 4 (4,4\%), 19 (21,1\%), dan $19(21,1 \%)$.

Berdasarkan pertanyaan, cara menguasai bahasa daerah dengan baik sangat beragam jawabannya. Sikap bahasa penutur terhadap pertanyaan itu, yaitu belajar dari orang tua dan teman, belajar sendiri dan di sekolah, sehari-hari digunakan bahasa Retta, berkomunikasi dengan baik, berbahasa dan dilindungi di dalam keluarga, sering berbicara dengan bahasa Retta, belajar dari orang-orang tua dan tokoh masyarakat, dan mengajarkan bahasa dengan baik supaya generasi muda bisa menguasai dengan baik. Berikut adalah parameter sikap bahasa penutur terhadap cara menguasai BD, yaitu bahasa Retta dengan baik.

\section{Tabel 4}

Sikap Bahasa Penutur Terhadap Cara Menguasai BD dengan Baik

\begin{tabular}{|c|c|c|c|c|c|c|c|c|c|c|c|c|c|c|c|c|}
\hline \multirow{3}{*}{\multicolumn{2}{|c|}{ No Parameter }} & & & \multicolumn{4}{|c|}{ Laki-Laki } & \multicolumn{2}{|c|}{ Total } & \multicolumn{5}{|c|}{ Perempuan } & \multicolumn{2}{|c|}{ Total } \\
\hline & & \multicolumn{2}{|c|}{$\leq 25$ thn } & \multicolumn{2}{|c|}{$26--50$} & \multicolumn{3}{|c|}{$\geq 51 \mathrm{thn}$} & \multicolumn{6}{|c|}{$\leq 25$ thn $0^{6--5} \geq 51$ thn } & \multirow[b]{2}{*}{$\mathrm{F}$} & \multirow[b]{2}{*}{$\%$} \\
\hline & & $\mathrm{F}$ & $\%$ & $\mathrm{~F}$ & $\%$ & $\mathrm{~F}$ & $\%$ & $\mathrm{~F}$ & $\%$ & $\%$ & $\mathrm{~F}$ & $\%$ & $\mathrm{~F}$ & $\%$ & & \\
\hline 1. & Pengguna & 3 & 3,3 & 22 & 24,5 & 7 & 7,7 & 32 & 35,66 & 6,7 & 36 & 40 & 10 & 11,1 & 52 & 57,8 \\
\hline 2. & Transmisi & & & & & 3 & 3.3 & 3 & 3.31 & 1.1 & 2 & 2.2 & & & 3 & 3.3 \\
\hline & Jumlah & 3 & 3,3 & 22 & 24,5 & 10 & 11,1 & 35 & 38,97 & 7,8 & 38 & 42,2 & 10 & 11,1 & 55 & 61,1 \\
\hline
\end{tabular}

Tabel 4 memperlihatkan parameter penggunaan pada penutur laki-laki kelompok usia 26-50 tahun tampak dominan, yaitu 22 (24,5\%). Parameter transmisi pada penutur laki- laki kelompok usia > 51 tahun tampak dominan, yaitu 3 (3,3\%). Sementara itu, parameter penggunaan dan transmisi pada penutur perempuan kelompok usia 26-50 tahun tampak dominan, yaitu $36(40 \%)$ dan $2(2,2 \%)$.

Berdasarkan pertanyaan terhadap 90 responden tentang cara menggunakan bahasa daerahnya dalam upacara adat, yaitu diselang-seling dengan bahasa Indonesia disesuaikan dengan situasi dan kondisi, digunakan bahasa daerah selama upacara adat (perkawinan dan kematian), digunakan dalam adat perkawinan dan kematian dan dijelaskan dengan bahasa Indonesia, memberi saran bagi pemerintah, menggunakan 
bahasa Indonesia, memberikan pemahaman kepada masyarakat dalam menggunakan upacara adat perkawinan dan kematian, digunakan dalam acara pemberkatan di gereja. Berikut adalah parameter sikap bahasa penutur terhadap cara mengunakan BD, yaitu bahasa Retta dalam upacara adat.

Tabel 5

Sikap Bahasa Penutur Terhadap Cara Menggunakan BD dalam Upacara Adat

\begin{tabular}{|c|c|c|c|c|c|c|c|c|c|c|c|c|c|c|c|}
\hline \multirow[t]{3}{*}{ No. } & \multirow[t]{3}{*}{ Parameter } & & \multicolumn{5}{|c|}{ Laki-Laki } & \multicolumn{2}{|c|}{ Total } & \multicolumn{5}{|c|}{ Perempuan } & \multirow[t]{2}{*}{ Total } \\
\hline & & \multicolumn{2}{|c|}{$\leq 25$ thn } & \multicolumn{2}{|c|}{$26--50$} & \multicolumn{2}{|c|}{$\geq 51$} & \multicolumn{5}{|c|}{$\leq 25$ thn 0} & \multicolumn{2}{|c|}{$\geq 51$} & \\
\hline & & $\mathrm{F}$ & $\%$ & $\mathrm{~F}$ & $\%$ & $\mathrm{~F}$ & $\%$ & $\mathrm{~F}$ & $\%$ & $\%$ & $\mathrm{~F}$ & $\%$ & $\mathrm{~F}$ & $\%$ & $\%$ \\
\hline 1. & Penggunaa & & 4,4 & 23 & 27,7 & & 8,8 & 35 & 38,96 & 6,7 & 39 & 43,3 & 9 & 10 & 5460 \\
\hline & Jumlah & 4 & 4,4 & 23 & 27,7 & 8 & 8,8 & 35 & 38,96 & 6,7 & 39 & 43,3 & 9 & 10 & 5460 \\
\hline
\end{tabular}

Tabel 5 memperlihatkan parameter penggunaan pada penutur laki-laki kelompok usia 26-50 tahun tampak dominan, yaitu 23 (27,7\%). Satu responden penutur perempuan kelompok usia >51 tahun menyatakan dengan cara menggunakan bahasa Indonesia. Sementara itu, parameter penggunaan pada penutur perempuan kelompok usia 26-50 tahun tampak dominan, yaitu 39 (43,3\%).

Sikap bahasa aparat pemerintah terhadap bahasa Retta dapat diketahui pandangannya terhadap sebelas butir pertanyaan. Pendapat aparat pemerintah terhadap butir soal yang pertama, yaitu persentasi penutur laki-laki dan perempuan bahasa Retta dijawab beragam. Pendapat aparat pemerintah adalah penutur laki-laki 60\%, 40\%, $45 \%, 80 \%$ dan penutur perempuan $40 \%$, 60\%, 55\%, 20\%. Data yang diperoleh tentang penutur bahasa Retta di Kampung Ternate Selatan yang berjenis kelamin laki-laki (40\%) lebih sedikit daripada perempuan (60\%). Pendapat aparat pemerintah terhadap pertanyaan tentang bahasa Retta yang lebih bertahan hidup daripada bahasa lain karena bahasa daerah tidak pernah berubah, khusus di daerahnya bahasa Retta lebih bertahan hidup daripada bahasa lain dan di daerah lain bahasa Retta tidak bertahan atau hanya dimengerti, bahasa daerah perlu dilestarikan, masih banyak generasi yang akan terus melanjutkan penggunaan bahasa Retta tersebut, bahasa Retta sangat unik untuk dipelajari, ada generasi penerus sehingga berkelanjutan, bahasa dari leluhur yang sudah diatur dan dipakai selama ini, yang lebih banyak menggunakan adalah laki-laki yang selalu ada/menetap di kampung itu. 
Pandangan aparat pemerintah terhadap pertanyaan butir ketiga tentang peluang kebertahanan bahasa Retta adalah sebagai berikut. Dikatakan bahasa daerah tersebut berkelanjutan kepada generasi penerus untuk tidak lupa berbahasa daerah, bahasa ibu di daerah Retta tersebut, ada generasi penerus pengguna bahasa Retta itu selama generasi itu terus bertambah otomatis bahasanya terus bertahan, ada penutur bahasa lain yang senang berbahasa Retta sebagai bahasa rahasia/sandi, semua penduduk Retta atau sebagian besar dapat berbahasa Retta, meneruskan bahasa tersebut kepada generasi berikut, sebahagian besar penduduk menggunakannya, bahasa sehari-hari orang-orang di kampung Retta dan diwariskan dari generasi ke genarasi berikutnya.

Aparat pemerintah menjawab beragam terhadap butir pertanyaan keempat tentang anak atau keluarga responden belajar bahasa Retta. Bahasa daerah adalah bahasa ibu yang harus disampaikan kepada anak supaya tidak salah dalam menyampaikan ke orang tua, anak dan keluarga tidak belajar bahasa Retta kalau bertugas di daerah itu keluarga pasti mempelajarinya agar bisa berinteraksi dengan masyarakat lain, bahasa ibu perlu dipelajari untuk tahu dan dengan sendirinya bisa menuturkannya, anak dan keluarga fasih berbahasa Retta karena sebagian famili berasal dari Retta, ada keluarga yang bisa berbahasa Retta, mempererat hubungan keluarga dan kerabat, ada keluarga yang menggunakan bahasa Retta (Suami), tidak belajar karena sekeluarga telah merantau ke kota lain di luar Alor, untuk berkomunikasi atau berinteraksi dengan masyarakat lain, tidak tinggal di lingkungan yang berbahasa Retta.

Jawaban aparat pemerintah terhadap butir pertanyaan kelima tentang kemampuan responden dalam menulis bahasa Retta adalah sebagai berikut. Pandangan aparat pemerintah adalah ada yang bisa menulis dalam bahasa Retta, sebagai bahasa ibunya dan diajarkang: dalam pendidikan sekolah dasar, misalnya: makan adalah hori, minum adalah bai, tidur adalah sedikit-sedikit bisa menulis dalam bahasa Retta sebagai bahasa penutur lain dan ingin belajar, seperti elkede artinya 'makan', jema 'pergi', naga 'tidak', ilkede 'makan'; tidak bisa menulis dalam bahasa Retta karena digunakan di daerah itu saja (kampung tersebut); tidak bisa menulis dalam bahasa Retta karena tidak dibesarkan di Ternate Selatan, Kabupaten Alor. 
Pendapat aparat pemerintah terhadap butir pertanyaan keenam, yaitu jika bahasa Retta diajarkan di sekolah ada yang sangat setuju sekitar $30 \%$ dan setuju sekitar 50\%. Hal tersebut dikarenakan bahasa daerah merupakan bahasa lokal yang sering diucapkan di kampung, muatan lokal yang perlu dilestarikan, budaya bahasa yang perlu dilestarikan misalnya dalam kegiatan ekstrakurikuler, semua orang Pura bisa memahami arti dari bahasa Retta, dan budaya bahasa tidak hilang pada generasi mendatang. Ada yang tidak setuju sekitar 20\% karena ada kecemburuan dari daerah lain bahwa di Alor banyak bahasa dan bukan sebagai bahasa nasional.

Pandangan aparat pemerintah terhadap butir pertanyaan ketujuh tentang pendapat responden jika pemerintah melindungi bahasa Retta. Aparat pemerintah berpandangan sangat setuju sekitar 20\% dan setuju sekitar $80 \%$ karena bahasa daerah merupakan bahasa adat yang biasanya digunakan dalam perkumpulan orang-orang tua adat, budaya, sebagai aset yang tak ternilai harganya, menjadi salah satu pelajaran ekstrakurikuler, budaya bahasa harus dilindungi dan dilestarikan, bahasa penghubung dalam bermasyarakat, sudah dipakai dari zaman dahulu yang sudah baku, ciri khas daerah masing-masing, dan bahasa Retta adalah bagian kekayaan budaya bangsa Indonesia.

Berikut adalah pandangan aparat pemerintah terhadap butir pertanyaan kedelapan tentang pendapat responden jika etnis lain yang belajar atau berbicara bahasa Retta. Ada yang menjawab sangat setuju sekitar $40 \%$ dan setuju sekitar 60\%, yaitu untuk melestarikan bahasa daerah tersebut kepada etnis lain untuk mengerti bahasa daerah tersebut, pertanda ada keinginan yang besar untuk mengerti akan adat istiadat daerah Retta tersebut, bisa berkomunikasi dengan penduduk lokal, di Alor banyak suku dan masing-masing ada bahasanya, etnis lain boleh belajar meskipun sedikit agar pada saat orang menuturkan bahasa itu mereka dapat memahami artinya, bahasa itu tidak hanya diketahui oleh etnis tertentu, memperlancar interaksi sosial dalam masyarakat, bahasa tersebut bisa mempererat tali persaudaraan dalam bermasyarakat, bahasa itu bisa dikenal etnis lain, dan memperlancar interaksi sosial dalam pergaulan masyarakat.

Pendapat aparat pemerintah terhadap butir pertanyaan kesembilan tentang peran bahasa Retta terhadap bahasa Indonesia sangat beragam. Peran bahasa Retta terhadap bahasa Indonesia adalah $45 \%$ karena sering digunakan di kampung atau di pertemuan adat. Dikatakan pula tidak berperan terhadap bahasa Indonesia. Bahasa Retta merupakan bahasa pengantar bagi anak-anak sekolah dasar kelas 1 dan 2. Anak-anak sekolah dasar 
di Pura dan Ternate Selatan bisa menggunakannya untuk memperdalam bahasa Indonesia. Banyak penduduk di Retta lebih mengerti bahasa Retta daripada bahasa Indonesia.

Berikut adalah pendapat aparat pemerintah terhadap butir pertanyaan kesepuluh tentang peran bahasa Retta untuk meningkatkan taraf hidup masyarakat. Beragam pandangan aparat pemerintah, yaitu untuk meningkatkan taraf hidup masyarakat sekitar 60\% karena bahasa daerah digunakan sehari-hari oleh masyarakat di kampung, bahasa Retta sangat besar perannya dalam meningkatkan taraf hidup masyarakat di daerah tersebut, sebagai alat komunikasi antara sesama, bisa dipergunakan sebagai media komunikasi dalam melaksanakan berbagai aktivitas pelayanan, sebagian masyarakat Retta tidak fasih berbahasa Indonesia sehingga masyarakat Ternate Selatan umumnya harus bisa berbahasa Retta saat berhubungan khususnya pada saat transaksi di pasar, tidak terlalu berperan karena masyarakat Retta yang mengerti bahasa Indonesia yang bisa memasuki peluang usaha Pura umumnya, memperlancar interaksi sosial dalam pergaulan masyarakat, memperlancar interaksi sosialisasi dalam bermasyarakat, pergaulan dengan sesama warga baik yang ada di kampung maupun orang-orang perantau, dan semua warga menggunakan bahasa Retta bagi yang tinggal di kampung Ternate Selatan dan sebagian kecil orang-orang perantau juga masih tetap menggunakan bahasa Retta.

Berikut adalah pendapat responden terhadap butir pertanyaan kesebelas tentang pendapat etnis lain terhadap bahasa Retta. Ada yang berpandangan bahwa bahasa itu berbeda- beda karena masing-masing memiliki identitan kelompok, bahasa Retta mudah dimengerti oleh etnis lain, bahasa tersebut merupakan budaya bahasa yang perlu dilestarikan, etnis lain mempunyai niat baik untuk mempelajari dan bertutur dengan menggunakan bahasa Retta, bahasa Retta adalah bahasa yang unik kadang-kadang digunakan oleh masyarakat kampung lain sebagai bahasa kelakar, etnis lain saling mendukung dalam mengembangkan bahasa Retta, bahasa Retta merupakan kekayaan budaya bangsa yang harus dilestarikan dan melengkapi bahasa etnis lain, bahasa tersebut merupakan kekayaan budaya suatu daerah yang harus dikembangkan dan dilestarikan, dan aset budaya bangsa dan menggambarkan identitas suku bangsa.

\section{SIMPULAN}

Berdasarkan hasil temuan, parameter penggunaan, transmisi, dan impresi penutur bahasa Retta berjenis kelamin laki-laki dan perempuan berusia 26--50 tahun tampak 
dominan memiliki pandangan yang positif (1) terhadap bahasanya, yakni melakukan transmisi bahasa ibu antargenerasi, digunakan dalam kehidupan sehari-hari, dan melestarikannya; (2) cara menguasai bahasanya dengan baik, yaitu belajar bahasa ibu dari orang tua, tokoh adat, tokoh masyarakat, teman, sendiri, dan digunakan dalam kehidupan sehari-hari; (3) terhadap penggunaan bahasa Retta dalam upacara adat perkawinan dan kematian, yakni menggunakan bahasa Retta atau bahasa Retta dan bahasa Indonesia secara bergantian sesuai dengan situasi dan kondisi.

Pendapat aparat pemerintah terhadap bahasa Retta tentang jumlah penutur, kebertahanan, belajar, menulis, diajarkan di sekolah, dilindungi pemerintah beragam dan memiliki pandangan yang posisif. Misalnya, ada generasi penerus bahasa Retta, digunakan dalam lingkungannya, dilestarikan, dipelajari untuk mempererat kekeluargaan dan berkomunikasi dengan etnis lain, bisa menulis bahasa ibu, belajar agar bisa bahasa daerah lain, dan diajarkan di sekolah sebagai muatan lokal.

Aparat pemerintah berpendapat bahwa bahasa daerah berperan dalam ranah adat atau budaya dan bahasa pengantar bagi anak-anak sekolah dasar kelas permulaan untuk memahami bahasa Indonesia. Peran bahasa Retta untuk meningkatkan taraf hidup masyarakat adalah digunakan dalam bertransaksi di masyarakat Retta dan tidak terlalu berperan dalam memasuki usaha antaretnis. Sementara itu, aparat pemerintah menanggapi pendapat etnis lain terhadap bahasa Retta adalah saling mendukung dan harus dilestarikan.

Penelitian ini belumlah tuntas masih ada aspek kebahasaan yang belum diteliti, misalnya morfologi, sintaksis, semantik, dan pragmatik. Hasil temuan ini dapat dimanfaatkan masyarakat untuk meningkatkan mutu pemakaian bahasa daerah di Indonesia.

\section{DAFTAR PUSTAKA}

Anderso, Edmund A. (1985). Language Attitudes: Perspectives for the Language Teacher. Singapore: SEAMEO Regional Language Centre

Ayatrohaedi. 2002. Pedoman Praktis Penelitian Dialektologi. Jakarta: Pusat Bahasa.

Giles, Howard dan Andrew C. Billings. (2004). "Assessing Language Attitudes: Speaker Evalution Study" dalam Handbook of Applied Linguistics (Alan Davies dan Catherine Elder ed.).

Grimes, Barbara F., ed. (2010). Ethnologue. 14th ed. Dallas, Texas: SIL International.

Kurniawati, dkk. (2015). "Kajian Vitalitas Bahasa Retta di Pulau Ternate Selatan, Kabupaten Alor', Laporan penelitian. Jakarta: Badan Pengembangan dan Pembinaan Bahasa. 
SIL International. (2006). Bahasa-Bahasa di Indonesia. Jakarta: SIL International, Cabang Indonesia.

Sugiyono dan Sry Satriya Tjatur Wisnu Sasangka. (2011). Sikap Masyarakat Indonesia terhadap Bahasanya. Yogyakarta: Elmatera Publishing.

Suhardi, Basuki. (1996). Sikap Bahasa. Depok: Fakultas Sastra Universitas Indonesia. "Ternate, Alor Barat Laut, Alor". 2015. http:// id.wikipedia.org/wiki/ Ternate,_Alor_Barat_Laut,_Alor. Diunduh 9 September 2015.

Tim Penelitian Vitalitas Bahasa. (2015). "Kuesioner Penelitian Vitalitas Bahasa di Indonesia”. Jakarta: Pusat Pengembangan dan Pelindungan. 